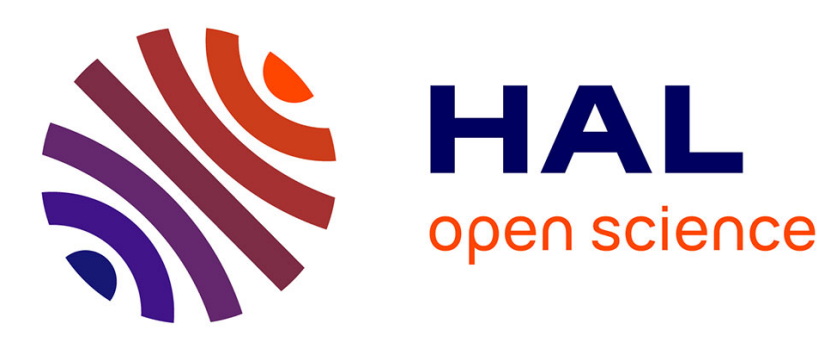

\title{
Configuration of a polymer grafted on a solid surface with specific adsorption of the free end \\ H. Hommel, A.P. Legrand
}

\section{To cite this version:}

H. Hommel, A.P. Legrand. Configuration of a polymer grafted on a solid surface with specific adsorption of the free end. Journal de Physique Lettres, 1982, 43 (12), pp.447-452. 10.1051/jphyslet:019820043012044700 . jpa-00232075

\section{HAL Id: jpa-00232075 https://hal.science/jpa-00232075}

Submitted on 1 Jan 1982

HAL is a multi-disciplinary open access archive for the deposit and dissemination of scientific research documents, whether they are published or not. The documents may come from teaching and research institutions in France or abroad, or from public or private research centers.
L'archive ouverte pluridisciplinaire HAL, est destinée au dépôt et à la diffusion de documents scientifiques de niveau recherche, publiés ou non, émanant des établissements d'enseignement et de recherche français ou étrangers, des laboratoires publics ou privés. 
Classification

Physics Abstracts

$68.45-61.40 \mathrm{~K}-05.90$

\title{
Configuration of a polymer grafted on a solid surface with specific adsorption of the free end $(*)$
}

\author{
H. Hommel and A. P. Legrand \\ Laboratoire de Physique Quantique (**), E.S.P.C.I., 10, rue Vauquelin, 75231 Paris Cedex 05, France
}

(Reçu le 29 juin 1981, révisé le 29 mars 1982, accepté le 22 avril 1982)

\begin{abstract}
Résumé. - Par la méthode des matrices de probabilité nous calculons les configurations d'un polymère greffé par une extrémité sur une surface solide, non adsorbé, à l'extrémité libre duquel on a fixé un marqueur de nature chimique différente, et adsorbé. Nous montrons comment le marqueur reste toujours très sensible à l'état de la chaîne à laquelle il est fixé, en calculant l'épaisseur de la couche adsorbée, le nombre de segments sur la surface et la probabilité relative du marqueur d'être sur la surface.
\end{abstract}

\begin{abstract}
By the probability matrix method we compute the configurations of a polymer grafted on a solid wall, and not adsorbed, with a label of different chemical nature fixed at the free end, and adsorbed. The fact that the label remains still very sensitive to the state of the chain to which it is fixed is shown, by computing the thickness of the adsorbed layer, the number of segments on the surface and the relative probability of the label being on the surface.
\end{abstract}

1. Introduction. - One of the experimental methods of studying the conformation of polymers adsorbed on a solid surface $[1,2,3]$ or chemically grafted by one end $[4,5,6]$ is the spin label technique. It consists, for example, in fixing a stable nitroxide free radical $[4,5]$ at the free end of a polyethyleneoxide chain, grafted onto a silica surface. The electronic spin resonance spectrum appears then as a superposition of two types of lines : broad lines characteristic of the slow tumbling of the adsorbed end segments and fine lines characteristic of the fast motion of the end segments in solution. The determination of the respective proportions of adsorbed and mobile segments allows then comparisons with the theoretical models for the segment concentration profile starting at the surface [7-10].

The greatest criticism that can be made against this technique is that the presence at the end of the chain of the label, of a chemical nature different from that of the monomer unit, and therefore differently adsorbed, so much alters the system being studied that no valid conclusion for the unlabelled system is possible any longer.

(*) La version française de cet article a été publiée aux Comptes Rendus de l'Académie des Sciences, 293, série II, p. 7 (1981); erratum, 294, série II, p. 481 (1982).

(**) ERA CNRS No 676. 
In this computation, we compare the situation where the label has the same adsorption energy on the surface as any monomer unit with the one where the end label is differently adsorbed and we point out how the information experimentally obtained can be useful even in the latter case.

2. Description of the model. - The introduction of a different adsorption energy for only one segment, i.e. of an energy proportional to the free end concentration but not to the total segment or end concentration is not very convenient within the limits of the mean field theories $[8,9,10]$. We have therefore chosen an equivalent numerical method.

A configuration of an ideal isolated polymer grafted on an adsorbing plane surface and consisting of $N$ links is represented by a random walk of $N$ steps on a cubic lattice and starting on the surface. When the excluded volume is thus neglected, the problem is essentially onedimensional in the direction perpendicular to the surface. In the same manner as Rubin [7], we distinguish the layer parallel to the surface and at a distance $k a$ (where $a$ is the length of a monomer unit and $k$ is integer) by the index $k$. And the unnormalized probability of the $n$-th link being in the $k$ layer is then determined by the recurrence formula :

$$
P_{k}(n)=\frac{1}{6} P_{k+1}(n-1)+\frac{2}{3} P_{k}(n-1)+\frac{1}{6} P_{k-1}(n-1)
$$

except on the adsorbing surface where the a priori probability is increased by a factor $\exp (\theta)$ (where $\theta=\varepsilon / k T$ and $\varepsilon$ is the adsorption energy of a monomer unit) :

$$
n \leqslant N-1 \quad P_{0}(n)=\frac{1}{6} \mathrm{e}^{\theta} P_{1}(n-1)+\frac{2}{3} \mathrm{e}^{\theta} P_{0}(n-1) .
$$

The possibility of a different adsorption energy $\eta$ for the last segment is introduced as follows

$$
P_{0}(N)=\frac{1}{6} \mathrm{e}^{\delta} P_{1}(N-1)+\frac{2}{3} \mathrm{e}^{\delta} P_{0}(N-1) \quad \delta=\frac{\eta}{k T} .
$$

Starting with $P_{0}(1)=1$ and $P_{k}(1)=0$ for $k \neq 0$ the concentration profile $P_{k}(n)$ was computed and the values corresponding to experimentally accessible quantities were derived from it.

The ratio of the probabilities of the end segment being in solution or being on the surface (measured by spin labelling) is :

$$
\text { Fast population/Slow population }=P_{\mathrm{f}} / P_{\mathrm{s}}=\left(\sum_{k=1}^{N} P_{k}(N)\right) / P_{0}(N) \text {. }
$$

The thickness of the adsorbed layer (measured for example by ellipsometry or hydrodynamic flow measurements) is defined by

$$
z=\left(\sum_{k=0}^{N} k P_{k}(N)\right) /\left(\sum_{k=0}^{N} P_{k}(N)\right) .
$$

Finally the mean number of segments on the surface (measured for example by fluorescence, infrared spectroscopy or nuclear magnetic resonance) is

$$
v=\sum_{n=1}^{N}\left(P_{0}(n) / \sum_{k=0}^{N} P_{k}(n)\right)
$$

We resort to the well known results [7, 9] for uniform adsorption of an isolated chain $(\eta=\varepsilon)$ and compare them with the limiting case where the label is the only adsorbed segment $(\varepsilon=0)$. The intermediate cases $\varepsilon \neq \eta$ are briefly discussed focusing our attention on the spin labelling technique. 
3. Results. - The improved results [11] for the characteristic quantities, ratio of the population of mobile labels to that of slow adsorbed ones, thickness, number of segments on the surface were obtained on a HP 9825 computer.

Whereas Rubin observed a very different behaviour for $\theta>\theta_{c}=0.1824$ where there is adsorption and for $\theta<\theta_{\mathrm{c}}$ where the chain is desorbed, the behaviour of the labelled chain evolves with the relative values of $\delta$ and $\theta$.

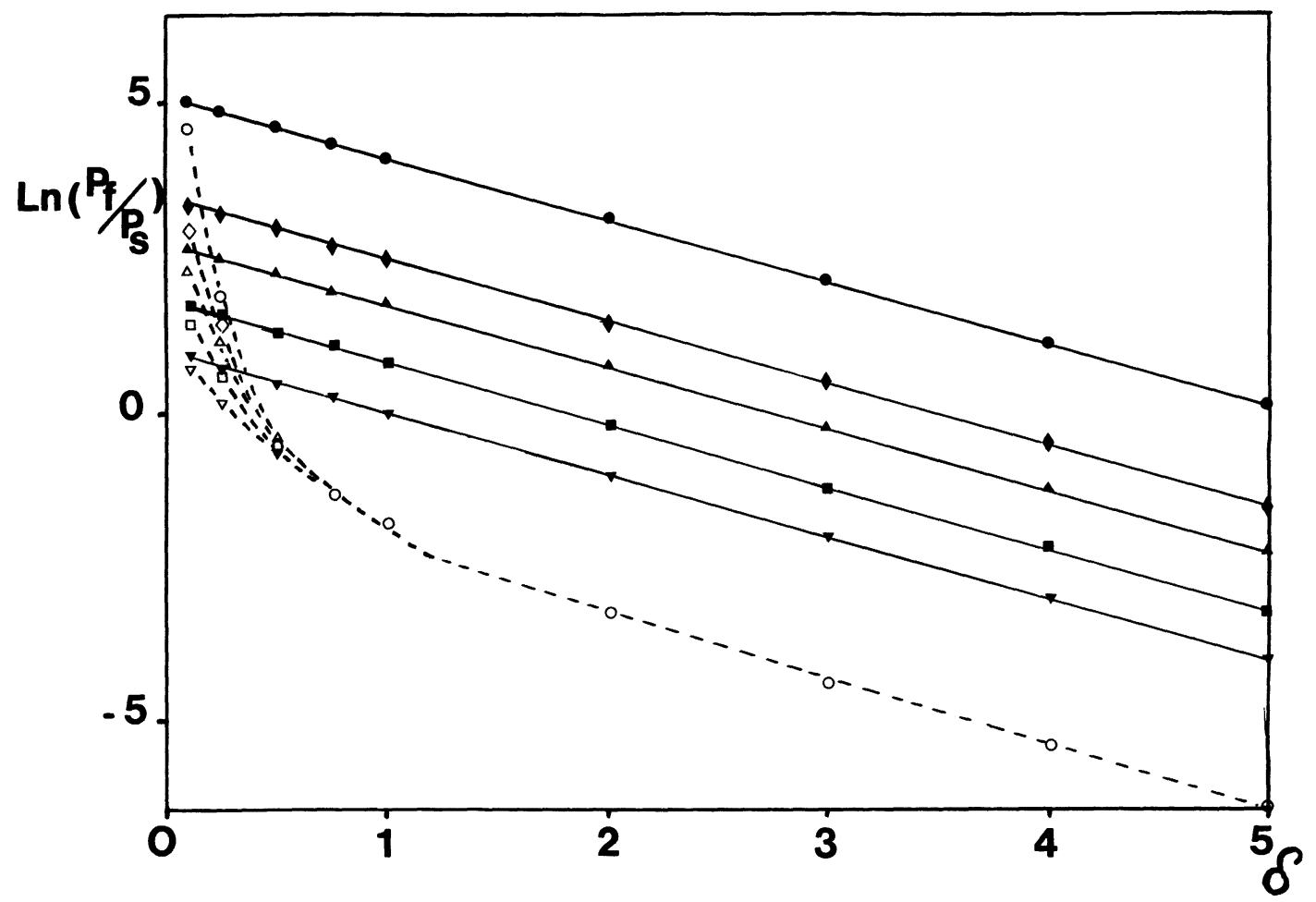

Fig. 1. - Ratio of fast to slow populations of label as a function of the adsorption parameter. Uniform adsorption : $(\theta=\delta),(N=10 \nabla),(N=20 \square),(N=50 \Delta),(N=100 \diamond),(N=500 \bigcirc)$. Specific adsorption of the label : $(N=10 \nabla),(N=20 \square),(N=50 \Delta),(N=100 \diamond),(N=500$ ).

The ratio of fast to slow populations of label (Fig. 1) is independent of the molecular weight for uniform adsorption $(\delta=\theta)$ i.e. unlabelled chains and is worth for $\theta \gg \theta_{\mathrm{c}} \operatorname{Ln} \frac{P_{\mathrm{f}}}{P_{\mathrm{s}}}=-\theta-1.4$. In the case of specific adsorption of the label only $(\theta=0)$ this ratio depends on $N$ and can be written $\operatorname{Ln} \frac{P_{\mathrm{f}}}{P_{\mathrm{s}}}=-\delta+\operatorname{Ln} N-1.4$. In the intermediate cases this ratio depends on a first term characteristic of the label and a second term characteristic of the state of the chain. The interpolation formula reads

$$
\operatorname{Ln} \frac{P_{\mathrm{f}}}{P_{\mathrm{s}}}=-\delta+f_{N}(\theta)-1.4
$$




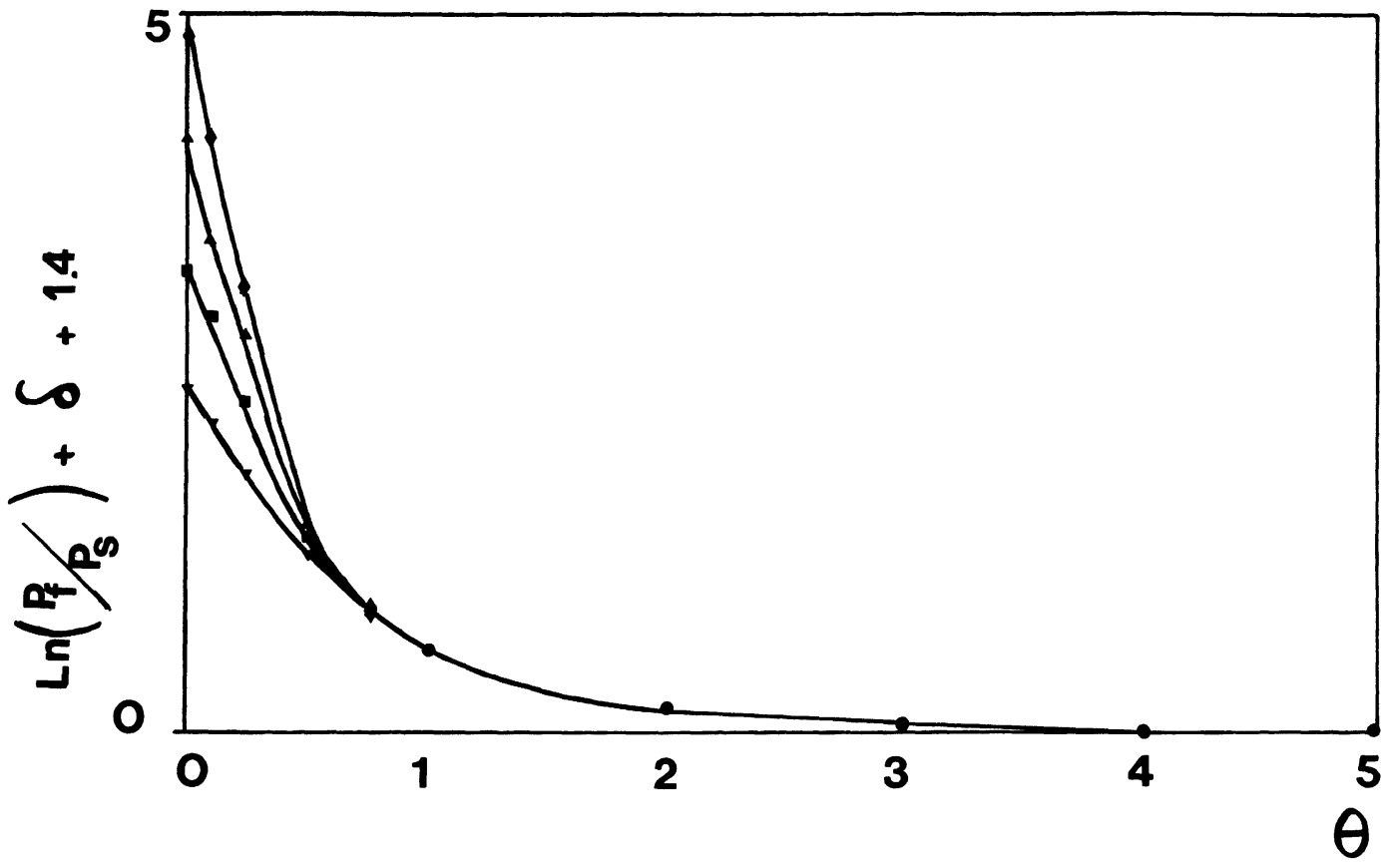

Fig. 2. - Term $f_{N}(\theta)$ in the ratio of fast to slow populations of label as a function of the adsorption parameter $\theta$, and is independent of $\delta$ in the range $\delta \in[0,10]:(N=10 \nabla),(N=20 \square),(N=50 \Delta),(N=100 \diamond)$.

where the computed function $f_{N}(\theta)$ (Fig. 2) is a fast decreasing function of $\theta$ and not of $\delta$ and $f_{N}(0)=\operatorname{Ln} N$.

If the experimental measurement of $\operatorname{Ln} \frac{P_{\mathrm{f}}}{P_{s}}$ as a function of the inverse of the absolute temperature is then possible in a sufficiently large range, the slope of the asymptotic straight line in the low temperature region is $\eta / k$. And the tangent at the point $(T \rightarrow \infty)$ with this asymptote $(T \rightarrow 0)$ defines the desorption temperature $T_{\mathrm{d}}$ related to $\varepsilon$ by $\frac{\varepsilon}{k}=-T_{\mathrm{d}} \frac{\operatorname{Ln} N}{f_{N}^{\prime}(0)}$.

Thus the configuration of the adsorbed chain is influenced by the spin label but in such a way that the actual configuration for unlabelled chains can be extracted from the results. Indeed if $\varepsilon$ and $\eta$ are known by another method, it is clear from the definition

$$
\frac{P_{\mathrm{f}}}{P_{\mathrm{s}}}=\frac{\sum_{k=1}^{N} P_{k}(N)}{P_{0}(N)}
$$

that the simple and general correction for removing the specific influence of the label is

$$
\left.\operatorname{Ln} \frac{P_{\mathrm{f}}}{P_{\mathrm{s}}}(\theta, N)\right|_{\text {unlabelled }} ^{\text {unain }}=\operatorname{Ln} \frac{P_{\mathrm{f}}}{P_{\mathrm{s}}}(\theta, N, \delta) \mid \begin{aligned}
& \text { labelled }+\delta-\theta . \\
& \text { chain }
\end{aligned}
$$

For the thickness (Fig. 3) Rubin observed a value depending on $\theta$ and independent of $N$. In the case of specific adsorption of the label only, we observe a variation of the type $z=\left(a \mathrm{e}^{\delta}+b\right)^{-1}$ where $a$ and $b$ are decreasing functions of $N$. 


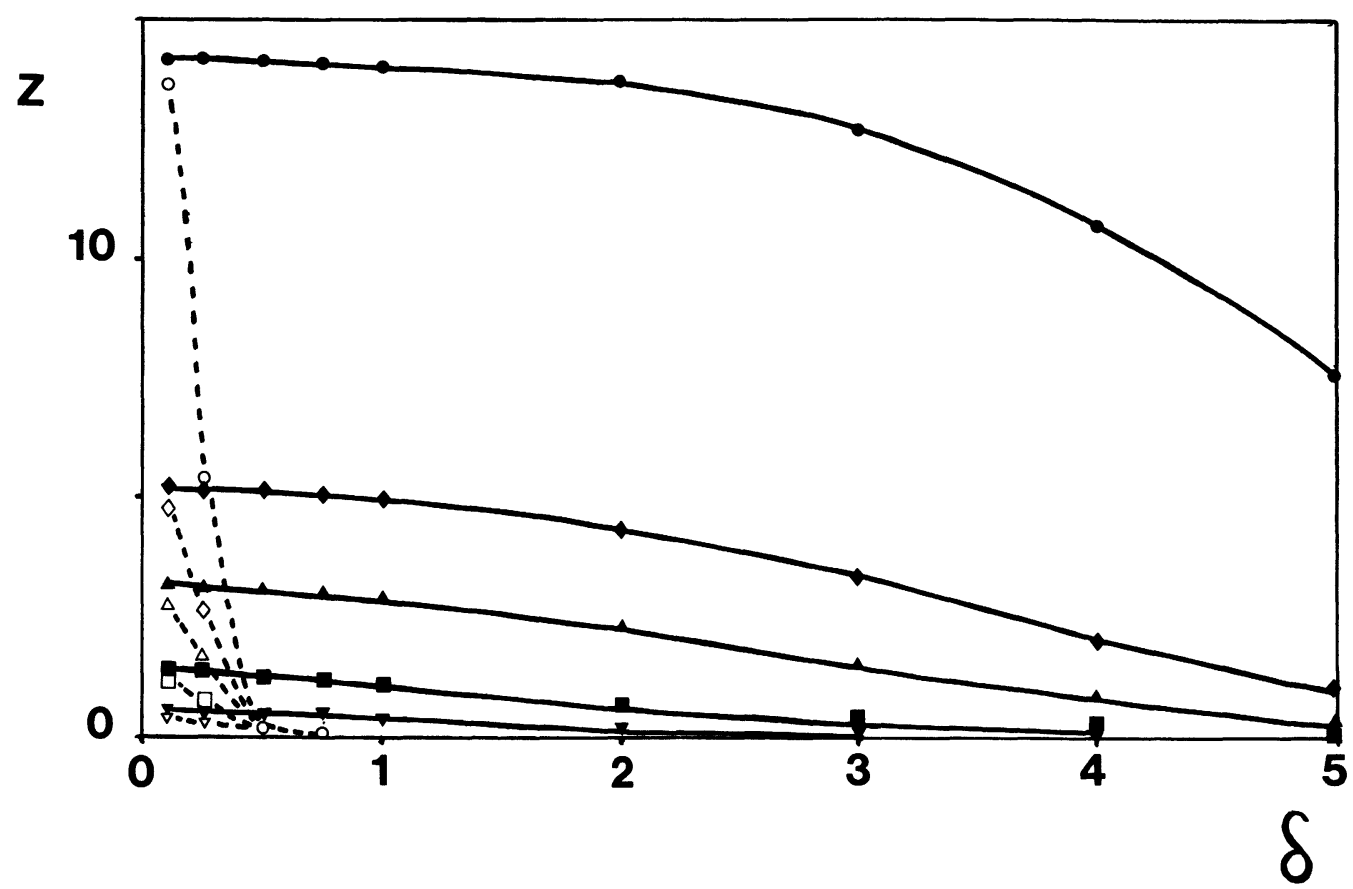

Fig. 3. - Thickness as a function of the adsorption parameter. Uniform adsorption : $(\theta=\delta),(N=10 \nabla)$, $(N=20 \square),(N=50 \Delta),(N=100 \diamond),(N=500 \bigcirc)$. Specific adsorption of the label $:(N=10 \nabla)$, $(N=20 \square),(N=50 \Delta),(N=100 \diamond),(N=500 \bullet)$.

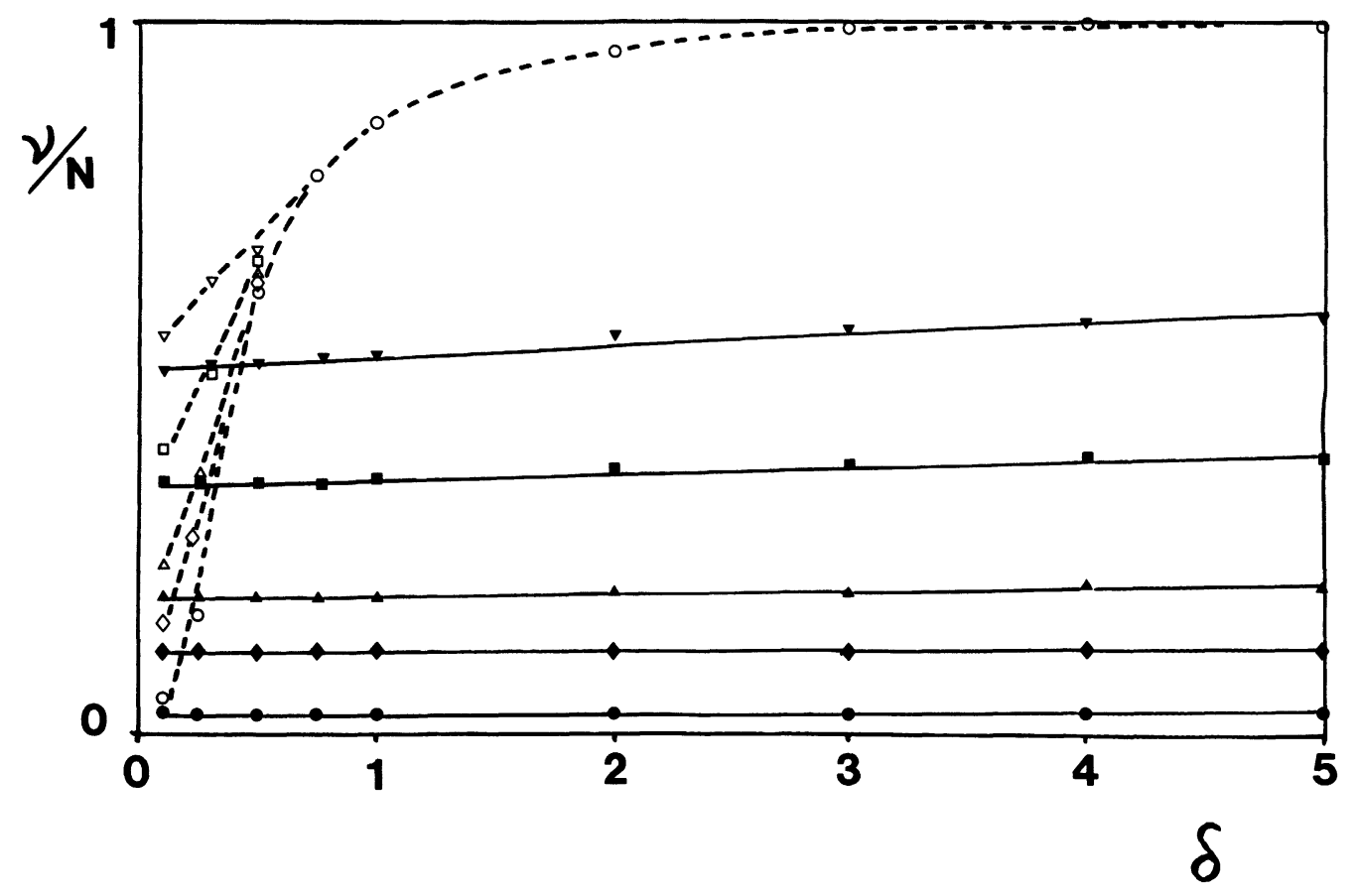

Fig. 4. - Number of segments on surface as a function of the adsorption parameter. Uniform adsorption : $(\theta=\delta),(N=10 \nabla),(N=20 \square),(N=50 \Delta),(N=100 \diamond),(N=500 \bigcirc)$. Specific adsorption of the label : $(N=10 \nabla),(N=20 \square),(N=50 \Delta),(N=100 \diamond),(N=500 \ominus)$. 
The mean number of segments on the surface (Fig. 4) varies like $v=N\left(1-\mathrm{e}^{-\theta-1}\right)$ for uniform adsorption. In the case of specific adsorption of the label only, the results we have fit very approximately the law $v=0.2 \delta+0.02 N+7$ in the studied region.

4. Conclusion. - Even in the case of specific adsorption of the end segment the polymer chain very much influences the physically measurable quantities. For the spin labelling technique the chain limits the free diffusion volume available to the label, i.e. acts by means of entropic factors. This technique continues to play its full part, giving indeed information about the state of the chain in the vicinity of the surface.

Acknowledgments. - P. Pincus has encouraged us to undertake this study and we had stimulating discussions with L. Facchini.

\section{References}

[1] Robb, I. D., Smith, R., Eur. Polym. J. 10 (1974) 1005.

[2] Clark, A. T., Robb, I. D., Smith, R., J. Chem. Soc. Faraday Trans. I 72 (6).

[3] Robb, I. D., SMIth, R., Polymer 18 (1977) 500.

[4] Hommel, H., Facchini, L., Legrand, A. P., Lecourtier, J., Eur. Polym. J. 14 (1979) 803.

[5] Hommel, H., Legrand, A. P., Lecourtier, J., Desbarres, J., Eur. Polym. J. 15 (1979) 993.

[6] Sistovaris, N., Riede, W. O., Sillesch, H., Ber. Bunsenges. Phys. Chem. 79 (1975) 882.

[7] Rubin, R. J., J. Chem. Phys. 43 (7) (1965) 2392.

[8] De Gennes, P. G., Rep. Prog. Phys. 32 (1969) 187.

[9] Lepine, Y., CAille, A., Can. J. Phys. 56 (1978) 403.

[10] Jones, I. S., Richmond, P., J. Chem. Soc. Faraday Trans. II 73 (1977) 1062.

[11] Hommel, H., Legrand, A. P., C.R. Hebd. Séan. Acad. Sci. Paris 293 (1981) 7.

Hommel, H., Legrand, A. P., C.R. Hebd. Séan. Acad. Sci. Paris 294 (1982) 481. 